ScIDice

\section{Survey On Knowledge, Awareness and Attitude Regarding Dental Stem Cell Therapy among Dental Students}

Research Article

Nikita Sivakumar ${ }^{1}$, M P Santhosh², Dhanraj Ganapathy ${ }^{3 *}$

${ }^{1}$ Intern, Department of Prosthodontics, Saveetha Dental College and Hospitals, Chennai - 600 077, India.

${ }^{2}$ Reader, Department of Oral Surgery, Saveetha Dental College and Hospitals, Chennai - 600 077, India.

${ }^{3}$ Professor and Head, Department of Prosthodontics, Saveetha Dental College And Hospitals, Saveetha Institute Of Medical And Technical Sciences Chennai, India.

\title{
Abstract
}

Stem cells can potentially differentiate into many different cell types in the body. Upon division, each new stem cell has the potential to either remain as a stem cell or become another type of cell with a more specialized function. In the oral cavity, the stem cell can be derived from dental pulp, apical papilla, and periodontal ligament or exfoliated from human deciduous teeth. Dental stem cells have been in light for regeneration of damaged dentin, pulp, resorbed root, periodontal regeneration and repair perforations. In addition, it has been also found that gingival mesenchymal stem cells have shown promising results in bone regeneration of mandibular defects and in suppression of inflammatory response. Through recent advances of stem cells, it has been possible for manipulation of salivary proteins and oral microbial colonization patterns. The aim of this study is to determine the awareness of dental students about stem cell therapy.It is to evaluate the level of understanding of dental students regarding stem cell therapy in dentistry.

Keywords: Dental; Stem Cells; Tooth; Therapy; Knowledge; Awareness; Attitude.

\section{Introduction}

With the ongoing advances, the medical team cannot afford to fall back in its research and development for a better cure for every disease. Thus, it began in the year 1961 where Drs. James Till and Ernset McCulloch discovered stem cells leading to the finding of a regenerative medicine [20]. Later in the year 2000, a researcher from National Institutes of Health brought to light the role of dentists in regenerative therapy by discovering stem cells in the dental pulp. Stem cells can be defined as clonogenic unspecialized cells which are capable of both self-replication and multi lineage differentiation [12].

It can be broadly classified into embryonic stem cells and adult stem cells. In addition to these stem cells present in the human body, there are stem cells which are artificially developed called Induced Pluripotent stem cells [18]. The embryonic stem cells and the Induced pluripotent stem cells are considered pluripotent stem cells referring to their ability to differentiate into any type of specialized cell. While the embryonic stem cells can be found in the embryonic stage the adult stem cells are obtained postnatal from an organ [17].

The adult stem cells can be classified into hematopoietic stem cells (HSCs) and non-hematopoietic mesenchymal stem cells (MSCs). The dental stem cells come under the mesenchymal stem cells. (Giuliani and Cedola, 2018) Dental stem cells can be obtained from various parts of the oral cavity: Dental Pulp Stem Cells (DPSC), Human Exfoliated Deciduous Teeth (SHED), Bone Marrow Derived MSCs From Orofacial Bone (BMSC), Periodontal Ligament Stem Cells (PDLSC), Dental Follicle Stem Cells (DFSC), Tooth Germ Progenitor Cells (TGPC), Stem Cells from Apical Papilla (SCAP), Oral Epithelial Progenitor (OESCS), Gingiva-Derived MSC, Periosteum Derived Stem Cells (PSC), and Salivary Gland derived stem cells (SGSC) [10].

Dental stem cells have served their purpose in both dentistry and treatment of other systemic diseases. Furthermore, the dental stem cells when compared to the other stem cells have a rather less serious ethical, social or scientifically concerns which has led

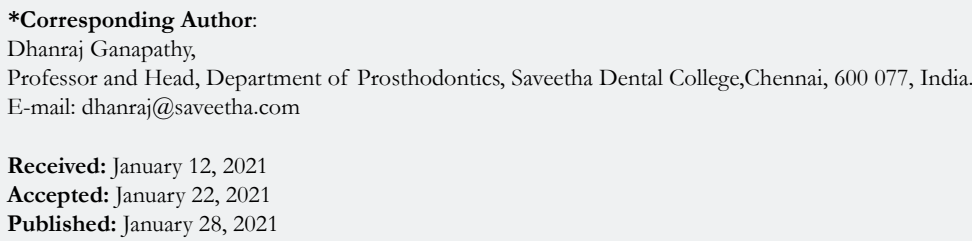

Copyright: Dhanraj Ganapathy ${ }^{\circ} 2021$. This is an open-access article distributed under the terms of the Creative Commons Attribution License, which permits unrestricted use, distribution and reproduction in any medium, provided the original author and source are credited. 
to an increase in dental stem cell banking [9]. Having known that, it has all the more reasons for a dentist to be paying attention to this new innovation of regenerative medicine [11].

\section{Materials and Method}

The present study was a questionnaire-based survey which was conducted in December 2017. The survey was conducted in English language and with a composition of 21 questions. The questions were formulated after reviewing many published articles related to dental stem cells $[1,2]$. As for the sample population, it comprised 150 dental students from Saveetha Dental College of Chennai City, India. The first 4 questions were based on their personal demographic details; name, age, gender and year of study in UG.

Following which the questions were focused on 3 aspects of the participating dental students; knowledge, awareness and attitude. The survey was close-ended, self-administered and hand delivered to the population. The questionnaire data were collected and tabled using Microsoft Excel 2010. Following which, using the raw data, statistical analysis was done and the total percentage and differences were noted to assess the knowledge, awareness and attitude regarding dental stem cell therapy among dental students. Using help of tables and figure illustrations such as bar charts and pie charts the data was differentiated.

\section{Results}

There were a total of 150 undergraduate dental students who had participated in this survey and out of which there were a total of
78 final year students, 19 third year students, 22 second year students and 31 first year students.

As seen from Figure 1, we can see that there is a minimal percentage difference in having knowledge towards stem cells in general $(93 \%)$ and dental stem cells $(83 \%)$ and also that most of the dental students of Saveetha Dental College (SDC) have been aware of stem cells and dental stem cells.

Figure 3 shows that the majority of the dental students agreed that their main source of stem cell knowledge has come through the exposure of internet (58\%) and conference/symposiums attended $(65 \%)$ while Television $(6 \%)$ ranked last for being an informative source of stem cells.

$45 \%$ of the dental student participants agreed that the source of dental stem cells (figure 4) in oral cavity is 'all of the above' that is the dental pulp, human exfoliated deciduous teeth, dental pulp, human exfoliated deciduous teeth, periodontal ligament, dental follicle, tooth germ progenitor cells, the apical papilla, oral epithelial progenitor, gingiva, periosteum and salivary gland. The second largest number of participants (34\%) did not know of the sources of dental stem cells. While another group of dental students opted for dental pulp, human exfoliated deciduous teeth and periodontal ligament individually. The least students believed in the presence of dental stem cells in dental follicle $(6 \%)$, tooth germ progenitor cells $(7 \%)$, apical papilla $(7 \%)$, gingiva $(0 \%)$, periosteum $(0 \%)$, oral epithelial progenitor cells $(0 \%)$ and salivary gland $(0 \%)$.

Figure 10 shows that a majority of participants $(36 \%)$ posted that application of stem cells in dentistry are 'all of the above' (sup-

Figure 1.

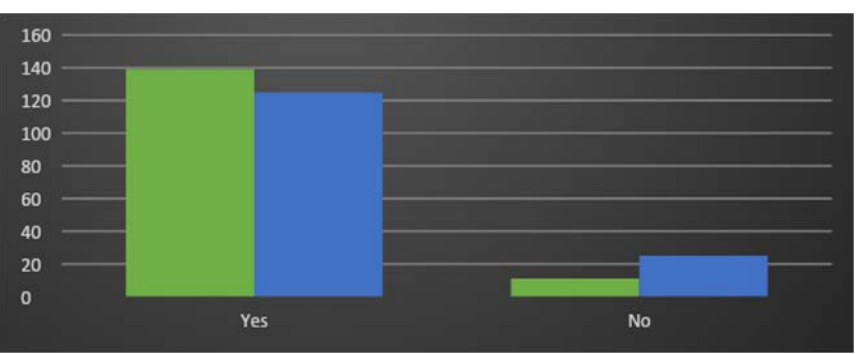

Figure 2 .

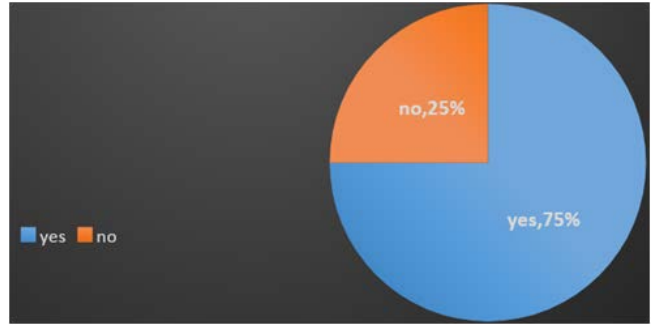

Figure 3.

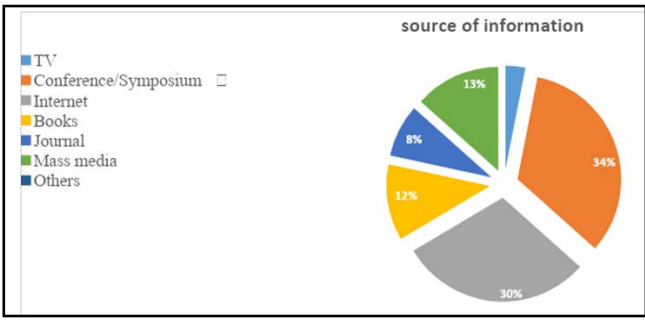


pression of the inflammatory response, missing tooth regeneration, craniofacial reconstruction, pulpal and dentin tissue regeneration, alveolar bone augmentation, bio-root engineering and reconstruction of the periodontium).

Subsequently, the next question of whether tooth is a good source of stem cells (figure 2) showed that the maximum of $75 \%$ agreed to this theory and when asked which kind of teeth is used for such procedures (figure 6), most decided on either tooth extracted due to non-pathological condition $(31 \%)$ or exfoliated teeth $(29 \%)$.

As seen in figure 7, numerous participants disapproved (20\%) and did not know $(47 \%)$ of the use of dental stem cells to develop non dental organs but knew (55\%) that they were used in treating systemic diseases. Hardly $11 \%$ of the dental students knew of stem cell banking procedure but were knowledgeable (58\%) of the information that stem cells can be collected from children
(Figure 8) and of them, $45 \%$ of the participants thought that it should be at the age group of 6-12 (Figure 9). According to Figure 13 , the main barrier in seeking dental stem cell treatment is due to insufficient knowledge of stem cells in dentistry (45\%). It seemed that more than $50 \%$ dental students were aware of stem cell banking in India.

Unlike such percentage variations, some options were chosen by a full $100 \%$ of the participating dental students, including that they were unknowledgeable of graft-versus-host disease and of certain drawbacks of dental implant which can be modified by using stem cells. Furthermore, this was also visible in the 'Awareness' section of the questionnaire where the 150 dental students displayed clear unawareness to Indian Council of Medical Research (ICMR) guidelines and of related ethical concerns (figure 11). However, their complete show of hands on educating themselves on dental stem cells exhibited their positive attitude.

Figure 4 .

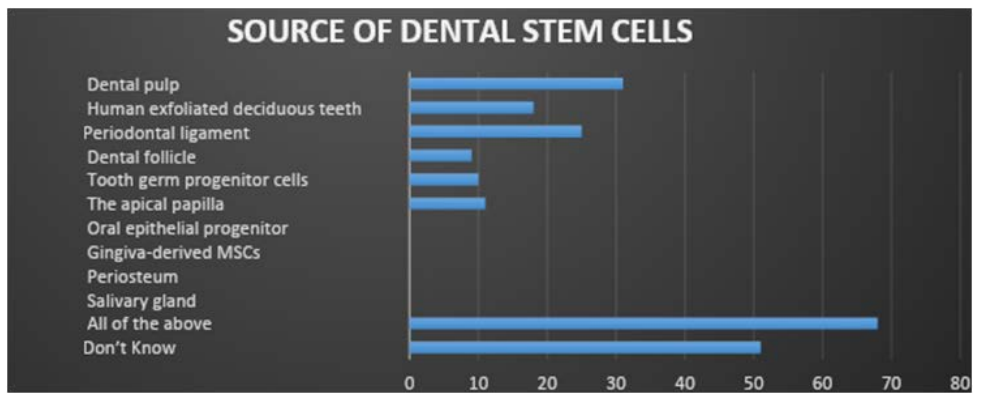

Figure 5.

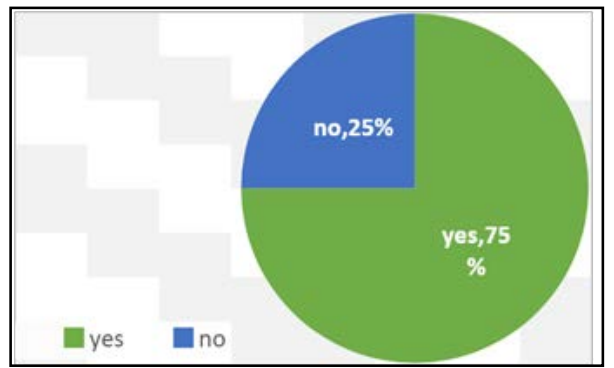

Tooth A Good Source For Stem Cells?

Figure 6.

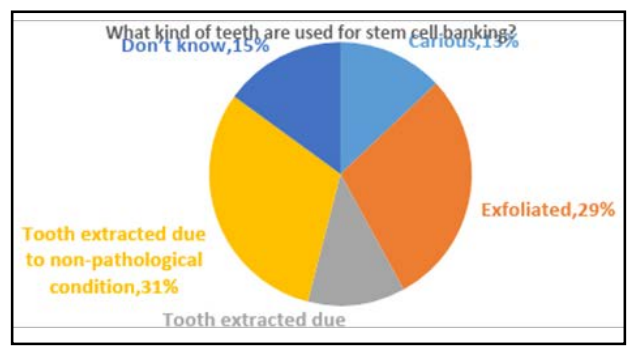

Figure 7.

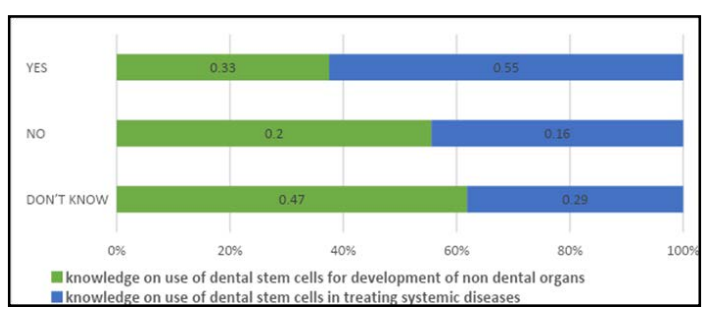


Figure 8.

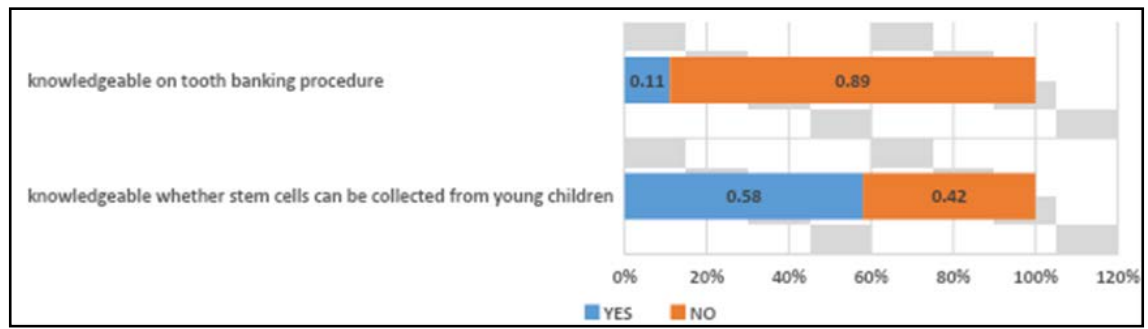

Figure 9.

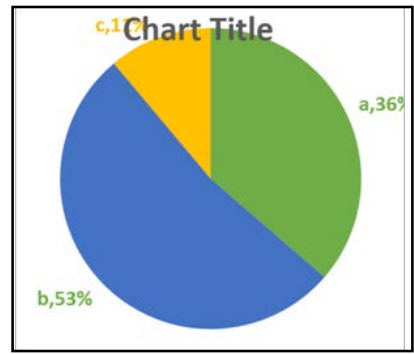

What age group of children are stem cells collected from? a: 0-6; b: 6-12; c: 12-18.

Figure 10.

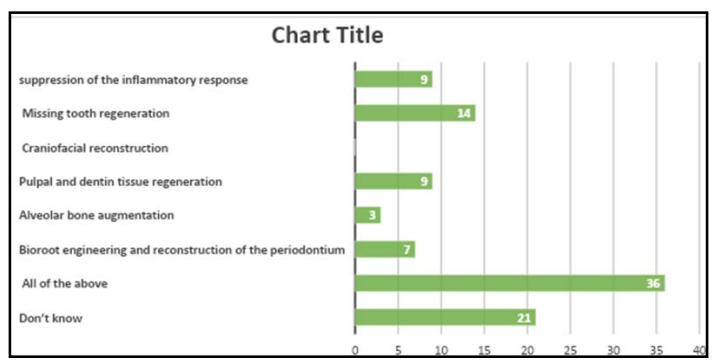

Figure 11.

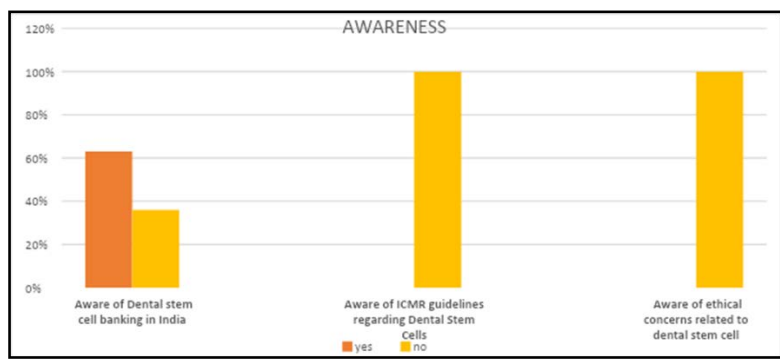

Figure 12.

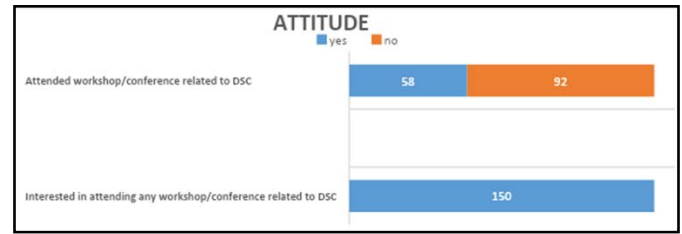

Figure 13.

Main barrier in seeking dental stem

cell treatment

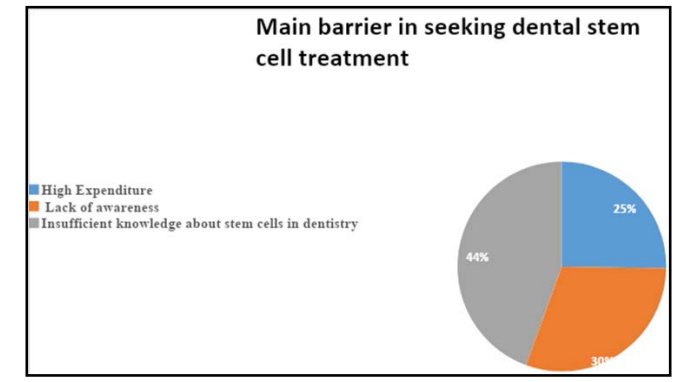




\section{Discussion}

The results showed that there is only a mere $10 \%$ more dental students knowing about stem cells in general than dental stem cells and that their total average value $(88 \%)$ of participants aware of these terms is greater than that of our pilot study $(80 \%)$ conducted in Terna Dental College and Hospital (Mumbai). In addition, for them their major source of dental stem cell information was through the internet $(32.4 \%)$ and journal $(32.6 \%)$ whereas for the Saveetha Dental participants conference and symposiums were their main source [6].

Although these 150 participants lack magnificently in the awareness based questions and in-depth knowledge based question, they can be corrected for they showcase a positive attitude towards enriching themselves. On the other hand, the correct answers of 'all of the above' to the questions on source of dental stem cells (figure 4) and the application of stem cells in dentistry (figure 10) could be assumed as a fluke value as many would have ticked that option for it seemed legibly an expected right answer. This can be considered as a measurement error [8].

A study done by Ankita Goyal of Haryana showed that their main barrier in seeking dental stem cell treatment is due to lack of awareness which contradicts in our participating population which believed that it is due to insufficient knowledge of stem cells in dentistry [2]. Thus, it is important to take measures to create awareness and continue it with workshops or conferences where one can gain sufficient updates on dental stem cells [15].

Among all the types of oral cavity based stem cells, the dental pulp stem cells (DPSC) are considered the most readily accessible type of stem cells which provides us an easy and minimally invasive way to obtain and store stem cells [22]. The dental pulp stem cells essentially originate from the cranial neural crest. Thus they are privileged with neural characteristics such as the expression of neurotrophins one of the most chosen type of oral stem cell seen in various therapies [4].

While we know that dental stem cellsare regenerative medicine, many do not know of the application of dental stem cells [19]. Dental stem cells can be used both in dental and systemic health enhancement. In dental, these stem cells can be used for the suppression of the inflammatory response, missing tooth regeneration, craniofacial reconstruction, pulpal and dentin tissue regeneration, alveolar bone augmentation, bio-root engineering and reconstruction of the periodontium [7].

Other than that, they can be seen creating an influence in developing non dental organs and in treating systemic diseases such as neurodegenerative disorders, ischemic heart disease, liver cirrhosis, diabetes mellitus and corneal blindness.(Aging and US Department of Health and Human Services; National Institutes of Health; National Institute on Aging, no date)Thus, it can be agreed that dental stem cells have more than enough benefits that can make storing our dental stem cells sound more necessary and reasonable [14].

It is a simple alternative to harvesting stem cells from other tissues. In addition to that, using our own stem cells for future inju- ries or diseases will remove the risks of graft-versus-host disease as there are chances of possible immune rejection [3]. These stem cells can easily be collected from children when they lose their baby tooth naturally through the exfoliation stage. Nevertheless, when it comes to deciduous teeth, extracted teeth are more preferable.

In children its best to get their teeth extracted before they become very loose as the dental pulp stem cells are more viable till they have the continuation of blood supply. 6-12 is the optimal age group for stem cell mining from children. In the case of adult teeth, only vital and non-pathological conditioned teeth are accepted. For extraction of such teeth, harvesting and isolation of the tooth takes place [13].

Harvesting is a process done to efficiently rule out any chances of infection and then isolation creates a sterile environment for the extraction process. The preservation measures of storing dental stem cells are by cryopreservation or magnetic freezing [16]. Cryopreservation is a process in which cells or whole tissues are preserved by cooling to subzero temperatures, typically $-196^{\circ} \mathrm{C}$. The preservation measures are done in labs of professional stem cell banks. These stem cell banks are also established in India at places such as ReeLabs and Stemade [21].

With regards to the 2017 national guidelines for stem cell research of India (ICMR) and ethical concerns, dental stem cells are more at benefit with lesser restrictions and ethical concerns. All the better reasons, for us to further research and advance in dental stem cells treatment. With the positive attitude of the 150 dental students changes can be made to change the factor of barrier in seeking dental stem cells.

\section{Conclusion}

Dental stem cells have promising future as regenerative medicine with so many research and studies showing the applications of dental stem cells with no or less complications. Similar to stem cells, dental stem cells too have the self-renewal and multipotent characteristics. However, the main reason why it is the best choice of stem cell is because unlike stem cells, dental stem cells don't have a flowing list of ethical and social concerns. Dental stem cells are becoming more known for being the most accessible type of stem cells which provides us with an easy, painless and minimally invasive way to obtain and store stem cells. Thus, all dentists should actively get involved in attaining and spreading the knowledge to make the best of dental stem cells.

\section{References}

[1]. Aging, U. S. D. of H. A. H. S. N. I. of H. N. I. on and US Department of Health and Human Services; National Institutes of Health; National Institute on Aging (no date) 'Alzheimer's Disease Neuroimaging Study Launched Nationwide by the National Institutes of Health', PsycEXTRA Dataset. doi: 10.1037/e492242006-001

[2]. Crow D. From cell stem cell to clinical trials: the biotech journey of two papers. Cell Stem Cell. 2017 Jun 1;20(6):746-8.

[3]. Egusa H, Sonoyama W, Nishimura M, Atsuta I, Akiyama K. Stem cells in dentistry--Part II: Clinical applications. J Prosthodont Res. 2012 Oct;56(4):229-48.Pubmed PMID: 23137671.

[4]. Fang D, Seo BM, Liu Y, Sonoyama W, Yamaza T, Zhang C, et al. Transplantation of mesenchymal stem cells is an optimal approach for plastic surgery. Stem Cells. 2007 Apr;25(4):1021-8.Pubmed PMID: 17170063.

[5]. Giuliani A, Cedola A, editors. Advanced High-Resolution Tomography in 
Regenerative Medicine: Three-Dimensional Exploration Into the Interactions Between Tissues, Cells, and Biomaterials. Springer; 2018 Nov 19.

[6]. Gomes JA, Geraldes Monteiro B, Melo GB, Smith RL, Cavenaghi Pereira da Silva M, Lizier NF, et al. Corneal reconstruction with tissue-engineered cell sheets composed of human immature dental pulp stem cells. Invest Ophthalmol Vis Sci. 2010 Mar;51(3):1408-14.Pubmed PMID: 19892864.

[7]. Gs, M, Mamatha, GS.'Questions and Answers in Community Dentistry'. 2010. doi: $10.5005 / \mathrm{jp} / \mathrm{books} / 11018$.

[8]. Huang YH, Yang JC, Wang CW, Lee SY. Dental stem cells and tooth banking for regenerative medicine. J Exp Clin Med. 2010 Jun 1;2(3):111-7.

[9]. Ikeda E, Yagi K, Kojima M, Yagyuu T, Ohshima A, Sobajima S, et al. Multipotent cells from the human third molar: feasibility of cell-based therapy for liver disease. Differentiation. 2008 May;76(5):495-505.Pubmed PMID: 18093227.

[10]. Iohara K, Zheng L, Wake H, Ito M, Nabekura J, Wakita H, et al. A novel stem cell source for vasculogenesis in ischemia: subfraction of side population cells from dental pulp. Stem Cells. 2008 Sep;26(9):2408-18.Pubmed PMID: 18583536

[11]. Kanafi MM, Rajeshwari YB, Gupta S, Dadheech N, Nair PD, Gupta PK, et al. Transplantation of islet-like cell clusters derived from human dental pulp stem cells restores normoglycemia in diabetic mice. Cytotherapy. 2013 Oct;15(10):1228-36.Pubmed PMID: 23845187.

[12]. Katge F, Shetty AJ, Rusawat B, Vamsi KC. Knowledge and attitude of Indian dentists regarding dental stem cells: A cross-sectional descriptive survey. Indian J Dent Res. 2017 Jul-Aug;28(4):367-374.Pubmed PMID: 28836526.

[13]. La Noce M, Mele L, Tirino V, Paino F, De Rosa A, Naddeo P, et al. Neural crest stem cell population in craniomaxillofacial development and tissue re- pair. Eur Cell Mater. 2014 Oct 28;28:348-57.Pubmed PMID: 25350250.

[14]. Laurence J, Baptista P, Atala A, editors. Translating regenerative medicine to the clinic. Academic Press; 2015 Nov 18.

[15]. McAllister, T, Atala, A.'Editorial: Future Directions for Stem Cell Banking and Therapy', Current Stem Cell Research \& Therapy.2016; pp. 2-2. doi:10 $.2174 / 1574888 \times 1201161207162504$

[16]. Mohamed A, Lynch E. Stem cell engineered implant dentistry-the future of implant dentistry. Stomatological Dis Sci. 2017 Sep 29;1:90-2.

[17]. Nesti C, Pardini C, Barachini S, D'Alessandro D, Siciliano G, Murri L, et al. Human dental pulp stem cells protect mouse dopaminergic neurons against MPP+ or rotenone. Brain Res. 2011 Jan 7;1367:94-102.

[18]. Oka K, Oka $S$, Chai Y. The role of TGF- $\beta$ signaling in cranial neural crest cells during mandibular and tooth development. J. Oral Biosci. 2009 Jan $1 ; 51(3): 143-50$.

[19]. Rai S, Kaur M, Kaur S. Applications of stem cells in interdisciplinary dentistry and beyond: an overview. Ann Med Health Sci Res. 2013 Apr;3(2):24554.Pubmed PMID: 23919198.

[20]. Sharma AR, Sharma S. Knowledge and attitude regarding periodontal diseases among undergraduate students of a dental college, Udaipur city. J. Dent. Res. 2018 Mar 19;5(3):63-7.

[21]. Sunil P, Manikandhan R, Muthu M, Abraham S. Stem cell therapy in oral and maxillofacial region: An overview. J Oral Maxillofac Pathol. 2012 Jan;16(1):58-63.Pubmed PMID: 22434942.

[22]. Tamaoki N, Takahashi K, Tanaka T, Ichisaka T, Aoki H, Takeda-Kawaguchi T, et al. Dental pulp cells for induced pluripotent stem cell banking. J Dent Res. 2010 Aug;89(8):773-8.Pubmed PMID: 20554890. 